\title{
MAGNET TECHNOLOGY DEMONSTRATION FOR AN IGNITION SINGLE-TURN TOKAMAK
}

\author{
M.D. Werst, G.W. Brunson, K.T. Hsieh, R.L. Sledge, \\ D.J. Wehrlen, W.F. Weldon, and H.H. Woodson \\ Center for Electromechanics \\ The University of Texas at Austin \\ 10100 Burnet Rd., Bldg. 133 \\ Austin, Texas 78758-4497 \\ (512) 471-4496
}

\begin{abstract}
The Center for Electromechanics at The University of Texas at Austin (CEM-UT) has designed, built, and is now testing a full torus, single-turn magnet designed to produce 20 Tesla (T) on-axis. The Ignition Technology Demonstration (ITD) as it is called is a 0.06 scale Texas Ignition Experiment (IGNITEX) toroidal field (TF) magnet prototype. The purpose of the ITD program is to demonstrate the operation of a $20 \mathrm{~T}$, single-turn TF coil powered by homopolar generators (HPGs). To date the prototype TF magnet has produced a purely toroidal, on-axis field of $15.0 \mathrm{~T}$ without an axial preload.
\end{abstract}

\section{INTRODUCTION}

The objective of the IGNITEX experiment ${ }^{1}$ is to prove the scientific feasibility of controlled thermonuclear fusion in a laboratory and to study a new regime of physics: fusion ignited plasmas. The ignition headroom in IGNITEX provided by a $20 \mathrm{~T}$ toroidal field gives a wide margin $(>200 \%)$ for all scaling laws except the original Goldston, for which ignition would require a larger device than originally proposed. The IGNITEX TF magnet is a $20 \mathrm{~T}$, single-turn, toroidal magnet powered by HPGs. ${ }^{2}$ Homopolar generators are inherently low voltage, high current, and ideally suited to fulfill the requirements of the IGNITEX single-turn magnet. Single-turn magnet technology is currently being demonstrated with a 0.06 scale IGNITEX TF magnet powered by an existing 9 MA HPG power sup. ply located in the CEM-UT laboratory. The 0.06 scale of the prototype $20 \mathrm{~T} \mathrm{TF}$ was selected based on the maximum current capability of CEM-UT's $60 \mathrm{MJ}$ HPG power supply which has a rating of 9 $\mathrm{MA}$ at $100 \mathrm{~V}$ in a parallel configuration. Stresses and temperatures reached in the scale $\mathrm{TF}$ coil are representative of those that would be experienced in a full scale IGNITEX TF coil with a $1.5 \mathrm{~m}$ major radius and a $5 \mathrm{~s}$ flat top current profile.
The advantages of a single-turn coil are numerous: first, no turn-to-turn electrical insulation is needed. Essentially $100 \%$ of the inner leg region of the coil is utilized for the high strength conductor. The design also attains a very high conductor filling ratio due to the elimination or absence of structural high-strength laminates, case structures, and coolant channels. The absence of insulation between conductors makes it easier to balance the bucking and wedging stress state of the magnet and allows the magnet to operate to higher temperatures. Even with essentially full utilization of the inner leg area, axial preload and precooling of the magnet to liquid nitrogen temperature are necessary to achieve $20 \mathrm{~T}$ on-axis for $5 \mathrm{~s}$. Electromechanical analysis of the IGNITEX TF magnet has shown that an $18 \mathrm{~T}$ on-axis field could be produced with no axial preloading. ${ }^{3}$ As of the writing of this paper, the prototype TF magnet (Fig. 1) has been operated to an on-axis field of $15.0 \mathrm{~T}$ without axial preload. The description of the ITD experiment, numerical simulation results, fabrication, and test results are presented.

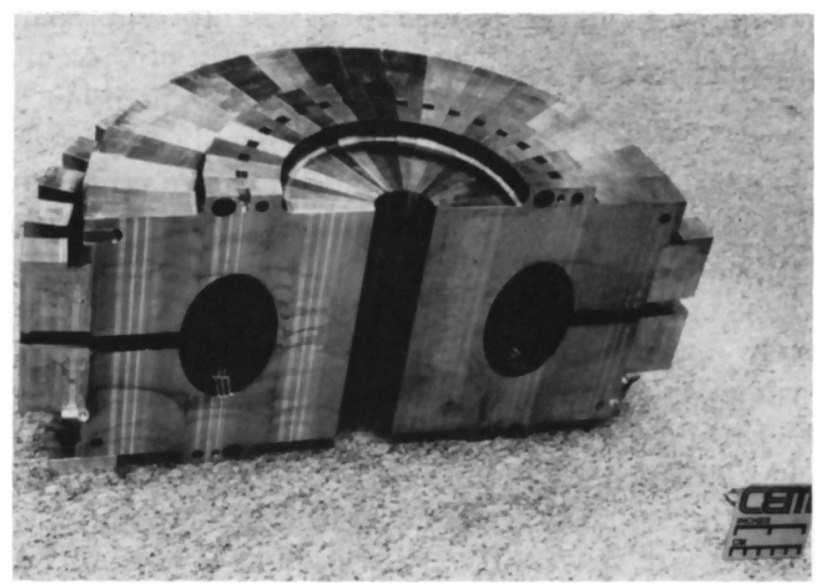

Figure 1. $180^{\circ}$ section of ITD TF magnet 


\section{DESCRIPTION OF THE MAGNET SYSTEM}

The ITD TF magnet prototype includes all the necessary components required to demonstrate the operation of a $20 \mathrm{~T}$, single-turn, TF magnet powered by HPGs. Homopolar generators (designed, developed and operated by CEM-UT) have been used for driving various pulsed power loads since 1973.4 The Balcones HPG power supply is comprised of six, drum type, 10-MJ generators, each rated at $100 \mathrm{~V}, 1.5 \mathrm{MA}$. The TF magnet (consisting of six, $60^{\circ}$ sectors) are connected to the six HPGs in a parallel configuration as shown in Figure 2. To extend the operational time of the TF coil, it is pool cooled to liquid nitrogen temperature. Heat is applied to the busbars between the TF coil and the HPGs using band heaters to prevent condensation from forming on the busbars and generators.

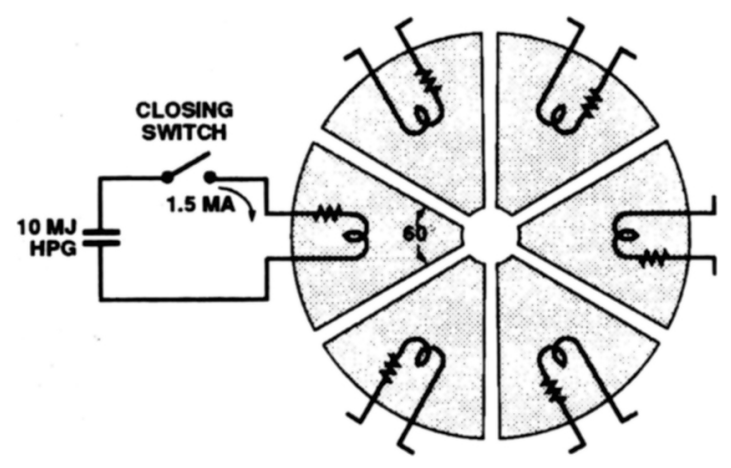

Figure 2. ITD power supply layout

High electromechanical and thermomechanical stresses in the inner leg of the TF coil are supported by efficient use of the inner leg area of the magnet, and by applying an axial preload. The preload requirement for the 0.06 scale is 420 tons in order to maintain an average axial compressive load of $50 \mathrm{ksi}$ over the inner leg area of the coil. 5 The preload is applied hydraulically to the inner leg of the TF coil via a composite thermal compression spacer at the top and bottom of the magnet. An external frame provides the axial containment and it is supported by a steel structure secured to the base of the HPG generator pit. The hydraulic system maintains the preload through the discharge, compensating for axial strain and thermal growth. A second preload is applied radially at the top and bottom of the TF magnet to hold the sectors together. The radial preload is applied by two rings which are thermally assembled over the coil sectors.
The ITD prototype is located in the base of the 9 MA HPG pit permitting the busbars to feed the device from above. The below ground level location permits other pulsed power experiments to continue using the generators without interference by the ITD magnet. A substantial amount of work was done early in the ITD project to adapt the existing generator busbars to support an experiment below ground level. ${ }^{6}$

A scale of 0.06 was selected for the prototype magnet based on the ratio of the current capability of the CEM-UT HPG system to the current requirements of IGNITEX TF coil (9 MA/150 MA). To produce the same on-axis $20 \mathrm{~T}$ toroidal field, the magnet dimensions are reduced by this factor. A second prototype with a scaling factor of 0.12 will succeed the 0.06 -scale prototype and will operate at $10 \mathrm{~T}$ when driven directly with the HPG power supply. The 0.12 scale TF coil is intended to demonstrate scaling relationships, large plate magnet conductor capability; provide a test-bed for a future poloidal field (PF) coil system; and serve as the load for a proposed 1 GJ homopolar module. 7 Operating parameters for the ITD and the small and large versions of IGNITEX are given in Table 1. Stresses for the ITD given in Table 1 take into account empirical circuit parameters and thermophysical properties of the $\mathrm{BeCu}$ conductor material.

Table 1. Critical parameters of IGNITEX toroidal field coils

\begin{tabular}{|l|c|c|c|}
\cline { 2 - 4 } \multicolumn{1}{c|}{} & $\begin{array}{c}\text { Technology } \\
\text { Demonstration }\end{array}$ & Small & Large \\
\hline Magnetic field on axis (T) & 20 & 20 & 20 \\
\hline Major radius (m) & 0.09 & 1.2 & 2.1 \\
\hline TF coil minor radius (cm) & 3.0 & 45 & 78 \\
\hline Bucking cylinder radius (cm) & 1.2 & 5 & 5 \\
\hline TF coil aspect ratio & 3.00 & 2.67 & 2.69 \\
\hline $\begin{array}{l}\text { Current pulse width } \\
\text { (s) (flat top) }\end{array}$ & 0.150 & $8(2)$ & $18(6)$ \\
\hline Peak current (MA) & 9.0 & 120 & 210 \\
\hline $\begin{array}{l}\text { Ave. current density } \\
\text { (inner leg) (MA/m^2) }\end{array}$ & 829 & 68.2 & 38.4 \\
\hline $\begin{array}{l}\text { Max. gtress } \\
\text { (von Mises) (ksi) }\end{array}$ & 90 & 93 & 93 \\
\hline Peak temperature ( $\left.{ }^{\circ} \mathrm{C}\right)$ & 187 & 154 & 158 \\
\hline Material (C17510) & BeCu & BeCu & BeCu \\
\hline
\end{tabular}

Even though current density in the TF magnet scales linearly with the scaling factor, stresses are identical as long as all the dimensions are scaled. Furthermore, as long as the time scaling factor is the square of the geometric scaling factor, the temperature, magnetic induction, and Mises stresses in the scaling model are an image of those for the full-scale model. Ideally, the physical history of the prototype would scale exactly to the full scale IGNITEX, but the existing circuit parameters of the BHPG system prevent this. Due to the geom- 
etry and layout of the existing busbars in the HPG pit, the circuit parameters of this experiment could not be reduced to accommodate the ITD current profile needs. A scaled current pulse for the 0.06 scale TF coil would be $36 \mathrm{~ms}$ long with an $18 \mathrm{~ms}$ flat top, as shown in Figure 3. A simulated HPG discharge current profile is superimposed in Figure 3 . The actual current profile provides approximately twice the ohmic heating necessary to demonstrate the magnet's capability. A compensating feature of the prototype TF magnet is the TF aspect ratio of 3.0 vs. 2.5 required for the full scale $\left(R_{m}=1.5 \mathrm{~m}\right)$ magnet. As a result, the additional energy in the TF magnet induce temperatures and stresses to levels that are representative of those predicted for the full scale IGNITEX TF magnets

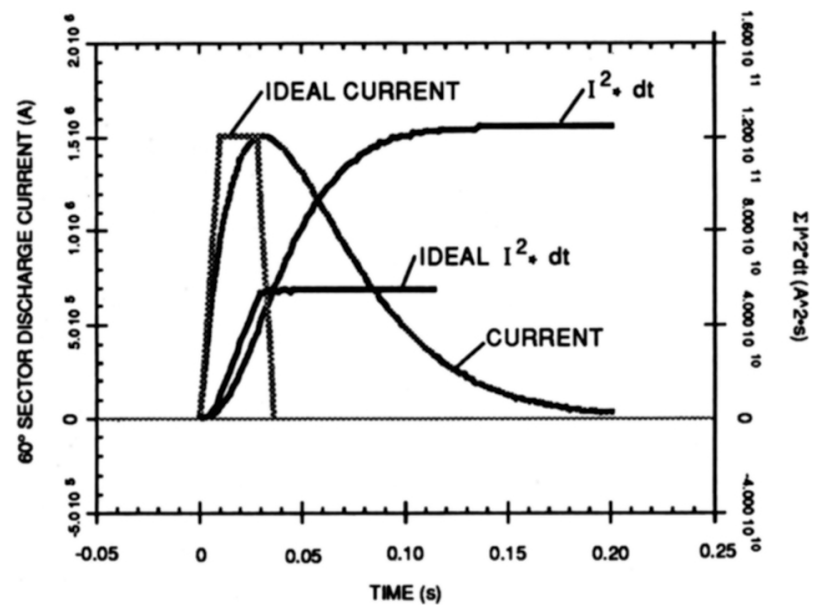

Figure 3. ITD current and profiles--simulated and ideal

To accommodate the fast current rise time of the HPG/TF magnet circuit, each HPG and $60^{\circ}$ sector is in series with an explosive closing switch. Typically, the HPG brush gear is used as the making switch when discharging into inductive loads. The ITD experiment requires a faster switch for its $\mathrm{di} / \mathrm{dt}$ of $50 \mathrm{MA} / \mathrm{s}$ and a time-to-peak of $30 \mathrm{~ms}$. A coaxial explosive switch was designed based on an existing, highly reliable switch used on other pulsed power experiments. 8

\section{TOROIDAL FIELD MAGNET DESIGN}

An attractive feature of the IGNITEX singleturn TF magnet design is its simplicity and robustness. The TF magnet consists of single-turn plates of high strength, high conductivity copper alloy. Complex casing support structures are not necessary to carry the electromagnetic loads, nor are sliding joints necessary to permit motion of the conductors. High field is attained by the efficient use of the inner leg area of the magnet, terminal clamping, and the use of an external axial preload structure. Electromagnetic forces produce large tensile loads in the inner leg of the TF coil, thus a compressive preload negates as much as $30 \%$ of this loading. Compressive loading is also achieved in the radial direction by use of a solid "bucking post". Since the IGNITEX PF magnet system is internal, a solid central post may be used, whereas a central ohmic heating coil dictates material properties and complicates the interaction between the PF and TF coils. Axial forces are also supported by clamps along the terminal leg. The terminal clamp provides both the axial support for the outer leg and clamping pressure for the electrical joint between the TF coil terminals and the buswork. A ring-type clamp on each individual TF coil plate maximizes both the clamp area and conductor area. Clamping pressure is produced by wedge jacks located above and below the terminals. A finger joint design is also utilized to provide adequate contact area at the joint. Ceramic spacers located between the TF coil terminals and between the terminals and the clamp provide electrical insulation and counter thermal contraction differences between the clamp and the terminals during the $\mathrm{LN}_{2}$ cool down.

Selection of the magnet conductor is based on trade-offs between electrical conductivity, yield strength, material stability, and available plate thickness. The 0.06 scale was fabricated from 1.25 in. thick plates of beryllium copper (Brush Alloy \#3 HT, Alloy C17510). The Brush Wellman alloy has demonstrated an electrical conductivity of $64 \%$ IACS at room temperature and an increase in conductivity by a factor of 2.3 at liquid nitrogen temperature. The material has a $0.02 \%$ yield strength of $108 \mathrm{ksi}$ at room temperature. Brush Wellman is currently producing 2.125 in. thick $\mathrm{BeCu}$ plates with minimum dimensions of $16 \times 17 \mathrm{in}$. for the 0.12 scale IGNITEX TF magnet demonstration.

\section{TEST OF FAST, HIGH CURRENT SWITCHING SYSTEM}

A test of the six explosive closing switches was performed in the generator pit prior to the first electrical test of the magnet. The purpose of the test was to verify mechanical integrity of the busbar/switch, to insure that explosive heat was contained well enough to prevent actual fire or an unnecessary response of the fire suppression system, and to observe switch-to-switch jitter times. Batteries and voltage probes were connected to each switch in order to record the time of closing. Switch-to-switch jitter of $0.02 \mathrm{~ms}$ was well below the desired maximum of $0.30 \mathrm{~ms}$, indicating that 
pulsing of the TF assembly would be well balanced. Explosive heat from the closing switch was adequately contained.

\section{TF MAGNET/HPG OPERATION}

Operation of the ITD TF magnet proceeds with the loading of the explosive closing switches. Switch loading and unloading has proved to be the most time-consuming aspect of testing the ITD magnet. Several hours are needed to complete this task. Liquid nitrogen precooling of the magnet proceeds once the switches are loaded. A brief checkout of the HPG system is performed and the busbar heater system is enabled. So as to prevent an excessive thermal gradient in the magnet or adjacent busbars, nitrogen gas is used initially to slow down the process. Liquid nitrogen flow to the cryostat is controlled by a $\mathrm{LN}_{2}$ level sensor/solenoid valve. The cool-down process takes approximately $45 \mathrm{~min}$. An exhaust system in the HPG pit prevents excessive oxygen dilution due to the nitrogen boil-off. With the magnet at $\mathrm{LN}_{2}$ temperature, the motoring sequence for the six HPGs is initiated. Figure 4 shows a typical HPG/TF magnet operating sequence for the ITD. To operate the power supply. the operator need only to provide input selection of the desired generator's speed and field current level. ${ }^{9}$ After a discharge, busbar heaters are reenabled and the magnet is brought back up to room temperature.

\section{TF MAGNET TESTING}

The testing program of the ITD TF magnet consists of three phases: low current, room temperature testing ( $\mathrm{B} \leq 11.0 \mathrm{~T})$; intermediate current with $\mathrm{LN}_{2}$ cooling testing, ( $\mathrm{B} \leq 15.0 \mathrm{~T}$ ); and high current with $\mathrm{LN}_{2}$ cooling and axial preloading testing $(\mathrm{B} \leq 20.0 \mathrm{~T})$. Due to the numerous experiments utilizing the CEM-UT, 9 MA HPG system, a limited number of tests can be performed in a given time frame. As of the writing of this paper, testing

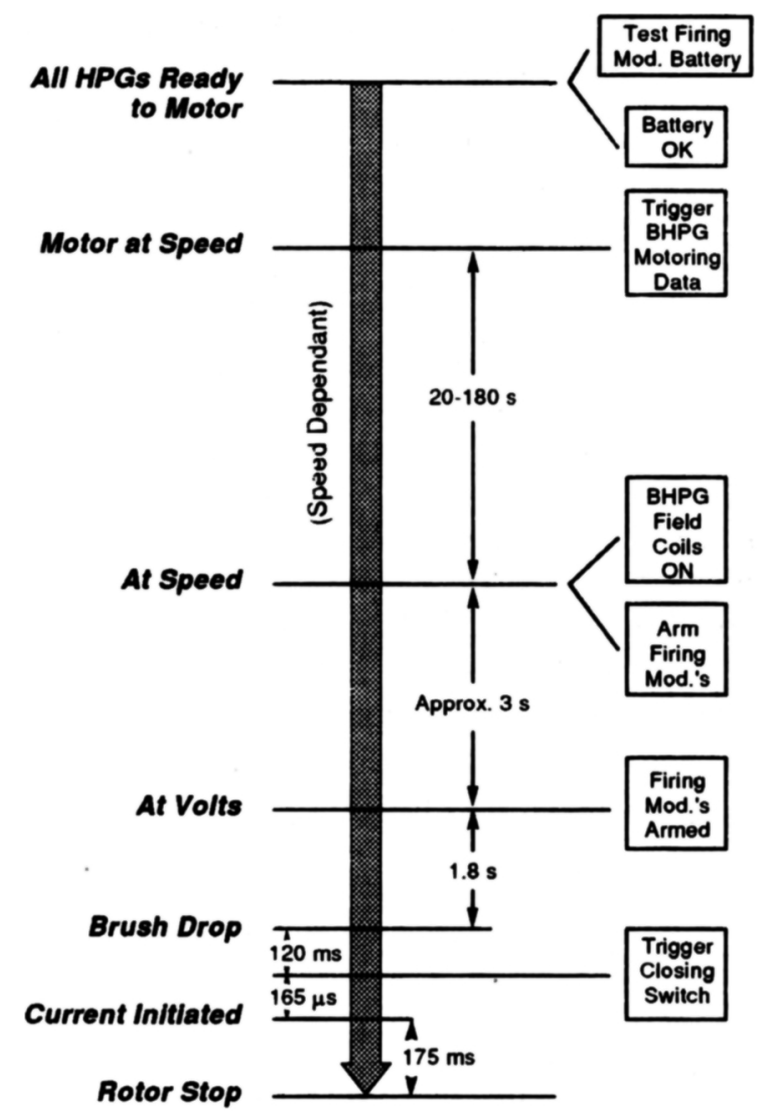

Figure 4. Typical HPG/ITD TF magnet operating sequence

through the intermediate current phase has been completed.

A summary of the ITD testing is given in Table 2. For reasons of space, the current, voltage and Hall probe data are shown only for test \#9. Homopolar instrument brush voltage for test \#9 $\left(\mathrm{LN}_{2}\right.$ cooled, 15.0 T) is shown in Figure 5. A prerequisite for the HPG system to permit a discharge is that the generator speeds matching to within a specified tolerance window. Any variation in the

Table 2. Summary of ITD testing

\begin{tabular}{|c|c|c|c|c|c|c|c|c|c|}
\hline & \multicolumn{5}{|c|}{ RoomTemperatureTesting } & \multicolumn{4}{|c|}{ LN $^{2}$ CooledTesting } \\
\hline Parameter/Test \# & Test \#1 & Test "2 & Test \#3 & Test " 4 & Test \#5 & Test $\# 6$ & Test 17 & Test *8 & Test $\$ 9$ \\
\hline Date of Test & $5 / 16 / 90$ & $6 / 4 / 90$ & $6 / 8 / 90$ & $6 / 11 / 90$ & $6 / 12 / 90$ & $7 / 26 / 90$ & $7 / 27 / 90$ & $7 / 30 / 90$ & $7 / 31 / 90$ \\
\hline HPG Speed (RPM) & 375 & 625 & 1125 & 1450 & 1800 & 375 & 1190 & 1712 & 2250 \\
\hline Ave. O.C. Volts (V) & 6.1 & 10.4 & 19.1 & 24.6 & 30.5 & 6.2 & 20.1 & 28.8 & 38.2 \\
\hline Peak Gen. Currents (kA) & 146 & 262 & 502 & 660 & 827 & 150 & 596 & 873 & 1126 \\
\hline Total Current (MA) & 0.88 & 1.57 & 3.01 & 3.96 & 4.96 & 0.90 & 3.58 & 5.24 & 6.75 \\
\hline TF Magnet Field (T) & 2.0 & 3.5 & 6.7 & 8.8 & 11.0 & 2.0 & 8.0 & 11.6 & 15.0 \\
\hline Max. Measured Temp $\left({ }^{\circ} \mathrm{C}\right)$ & $* * * *$ & 33 & 65 & 97 & 135 & -186 & -142 & -95 & -26 \\
\hline $\begin{array}{l}\text { B-Post bore Displacement } \\
\text { (max } @ \mathrm{t}=44 \mathrm{~ms})(\mathrm{mils})\end{array}$ & $* * * *$ & & $* * * *$ & 1.77 & 2.02 & 0.75 & 5.00 & 6.37 & 8.81 \\
\hline
\end{tabular}


HPG/TF magnet sector circuit parameters may be compensated by adjusting the respective HPG's field voltage. In this way, a field ripple, if any, can be corrected. Individual current profiles from test \#9 are shown in Figure 5.

The primary magnet diagnostics in the ITD experiment are the magnetic field, strain, and temperature measurements. The on-axis Hall probe data from test \#9 (Fig. 6) was produced using F.W. Bell Hall probes (BHT-921) calibrated with a $5 \mathrm{~cm}$, $20 \mathrm{~T}$, bitter magnet at the MIT, National Magnet Laboratory. It is believed that the field variation is the result of a radial positioning error of the Hall probe mounts. At $15 \mathrm{~T}$, the field gradient in the radial direction is $0.17 \mathrm{~T} / \mathrm{mm}$. An alternate method of supporting the Hall probes will be implemented for the high current phase of testing.

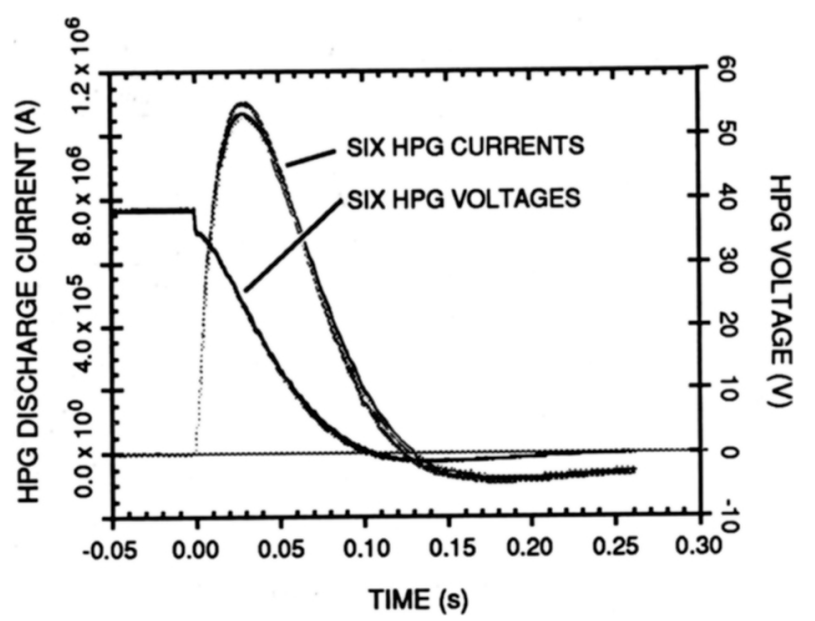

Figure 5. Six HPG voltages and currents for $15 \mathrm{~T}$ (test \#9)

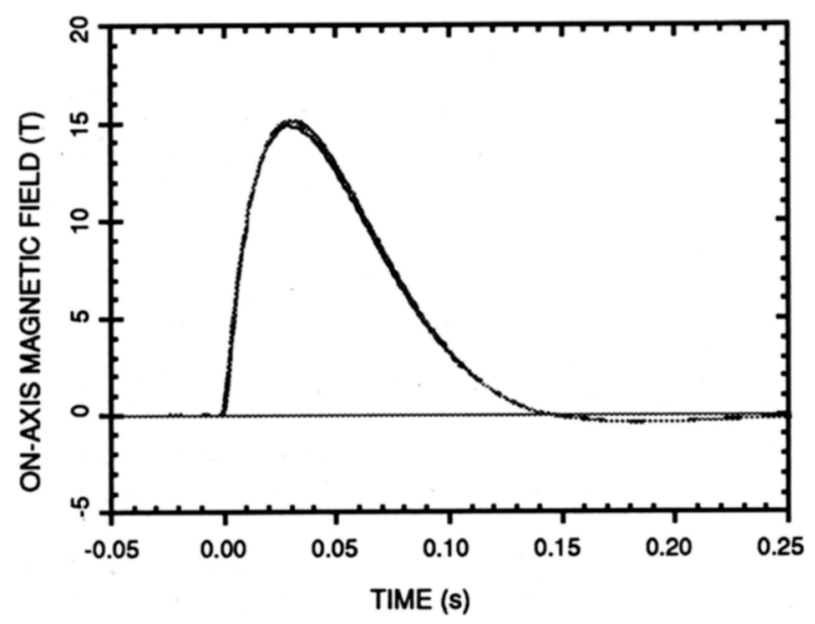

Figure 6. TF magnet Hall probe data from $15 \mathrm{~T}$ (test \#9)
Measured temperatures in the ITD TF magnet are consistently lower than predicted. It is believed that two factors may attribute to this result: thermocouple response time and the conservative assumptions associated with the computer model. Figure 7 shows profiles temperatures measured at several locations along the inner leg of the magnet for test \#9.

Inner leg axial strain data for tests \#2 through 5 is shown in Figure 8. Tests \#2 through 5 were room temperature tests up to $11.0 \mathrm{~T}$. The peak axial strains correspond very well to predicted values for the $3.5,6.7$, and $8.8 \mathrm{~T}$ tests. The predicted peak axial strain for the $11.0 \mathrm{~T}$ test is 2,490 $\mu \varepsilon$ compared to a peak of $2,250 \mu \varepsilon$ that was measured. It is believed that this phenomena may also

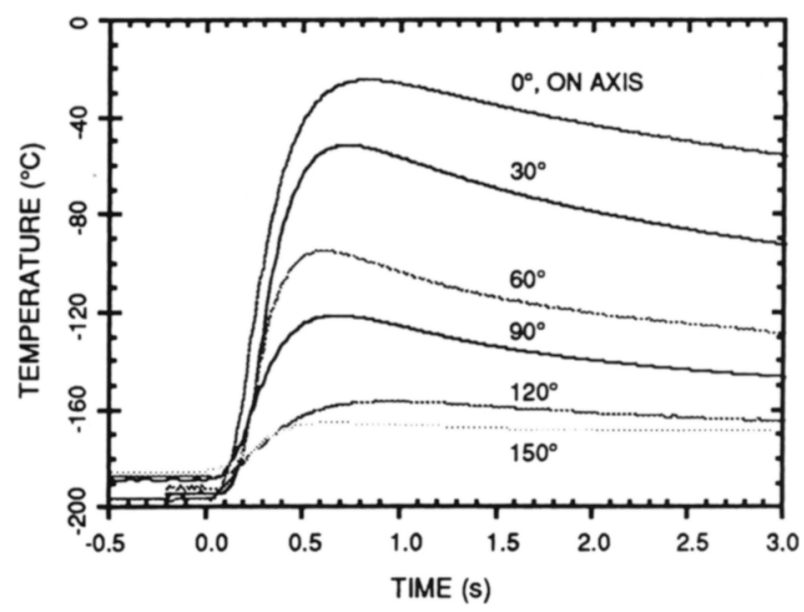

Figure 7. Inner leg thermal gradient for $15 \mathrm{~T}$ test (test \#9)--Surface temperatures of TF magnet; angles measured from major axis in poloidal plane

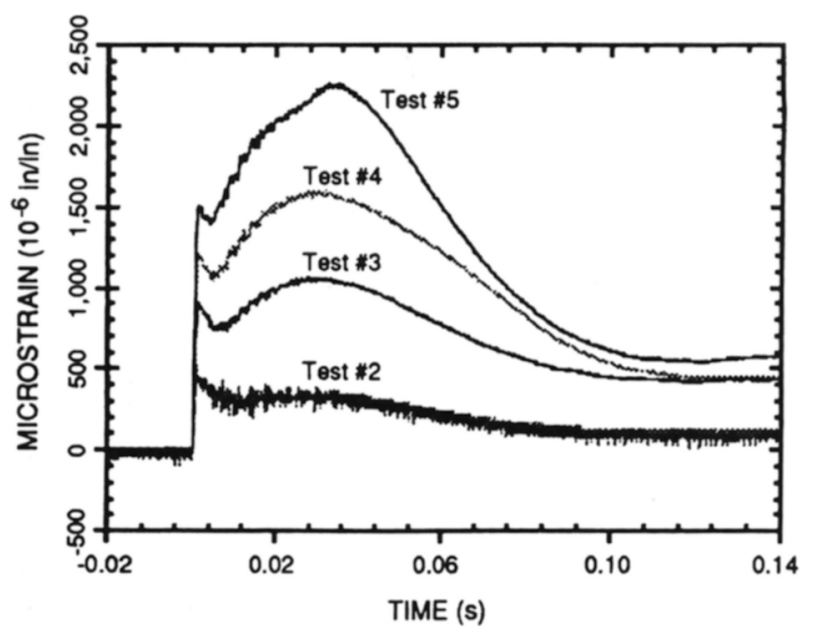

Figure 8. Inner leg axial strain data for tests \#2 to 15 
be attributed to lower temperatures in the magnet than predicted, resulting in noticeably lower thermal strains in the $11.0 \mathrm{~T}$ test.

Displacements of the central hole of the TF magnet are critical for sizing the bucking post. Diameter changes during a discharge are measured by strain gauges mounted to a proof ring installed in the central hole of the magnet. Results for tests 7,8 , and 9 are shown in figure 9 . The displacements correspond well with predictions of gap closing and magnet modulus.

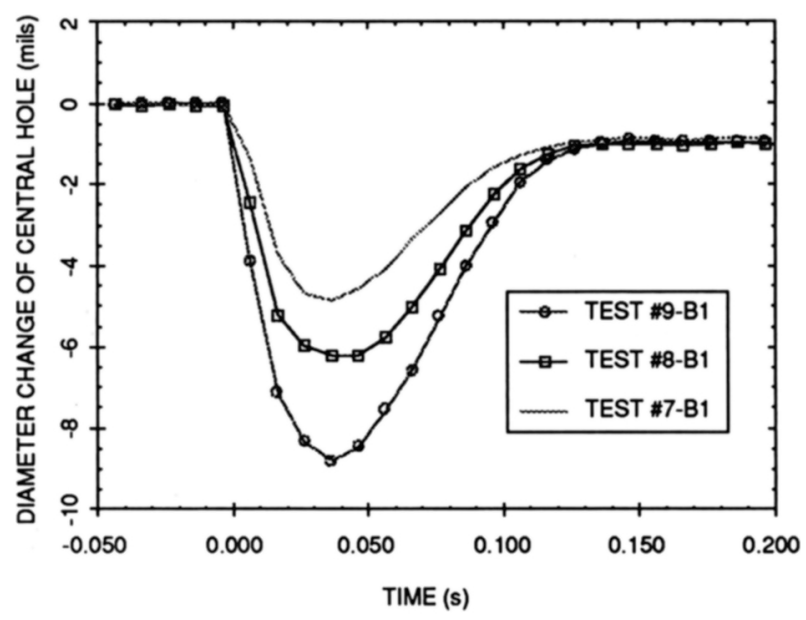

Figure 9. ITD TF magnet tests $7,8, \& 9 \mathrm{TF}$ magnet diametrical displacement

During the initiation of the high current testing, a design oversight was discovered in the transition busbars between the existing HPG busbars and the TF magnet. Thermal and electromagnetic loads in this region of the busbar system will require some design modifications. The high current testing phase will be realized later this year. The conductor region of concern is located where the busbar transitions from horizontal to vertical in close proximity to the TF magnet. This area has proved difficult because of lack of access for vertical busbar clamping. This aspect of the busbar configuration is unique to the ITD TF magnet experiment because of the peculiarities of the BHPG setup and is not related to the full scale TF magnet design and operation.

\section{CONCLUSION}

Synchronization of multiple HPGs into a single-turn toroidal magnet has been realized. Strain and temperature measurements indicate peak levels close to or below those predicted by the electrothermal and mechanical computer model. To date the full-torus, ITD magnet prototype has pro- duced fields up to $11.0 \mathrm{~T}$ on-axis without precooling and up to $15.0 \mathrm{~T}$ on-axis with magnet precooling. High current testing with precooling and preloading of the prototype magnet up to field levels of 20.0 $T$ is scheduled for later this year.

\section{ACKNOWLEDGMENTS}

This work is sponsored by the Texas Advanced Technology Program and the Texas Atomic Energy Research Foundation.

\section{REFERENCES}

1. M.N. ROSENBLUTH, W.F. WELDON and, H.H. WOODSON, "Basic Design Report of the Fusion Ignition Experiment (IGNITEX)," presented in Texas Atomic Energy Foundation Project Progress Report, March 1987.

2. R. CARRERA, et. al., "Description of the Scientific \& Technological Aspects of the Fusion Ignition Experiment IGNITEX," 9th Topical Meeting on the Technology of Fusion Energy, Oak Brook, IL, October 1990.

3. K.T. HSIEH, et. al., "Electromechanical and Thermomechanical Stress Analysis of the TF Magnet System in Single-Turn Ignition Tokamaks," 9th Topical Meeting on the Technology of Fusion Energy, Oak Brook, IL, October 1990.

4. J.H. GULLY, et. al., "HPG Operating Experience at CEM-UT," IEEE Transactions on Magnetics, Vol. Mag-22, No. 6, November 1986.

5. G.W. BRUNSON, et. al., "Development of Preloading and Precooling Systems for a SingleTurn Ignition Tokamak," 9th Topical Meeting on the Technology of Fusion Energy, Oak Brook, IL, October 1990.

6. R.L. SLEDGE, et. al., "High-Current Busbars for a Prototype Homopolar-Toroidal Magnet System for Fusion Ignition," 9th Topical Meeting on the Technology of Fusion Energy, Oak Brook, IL, October 1990.

7. W.A. WALLS, et. al., "Description of PulsedPower Homopolar Technologies for a Fusion Ignition Experiment," 9th Topical Meeting on the Technology of Fusion Energy, Oak Brook, IL, October 1990.

8. R.L. SLEDGE, et. al., "Experimental Data on High Power Explosive Opening and Closing Switches at CEM-UT," 7th IEEE Pulsed Power Conference, Monterey, CA, June 1989.

9. J.R. KITZMILLER, et. al., "Testing the $60 \mathrm{MJ}$ Pulsed HPG Supply at CEM-UT," 7th IEEE Pulsed Power Conference, Monterey, CA, June 1989. 